\title{
Relationship between human sperm motility characteristics and sperm penetration into human cervical mucus in vitro
}

\author{
D. Mortimer*, I. J. Pandya and R. S. Sawers \\ University Department of Obstetrics and Gynaecology, Birmingham Maternity Hospital, Edgbaston, \\ Birmingham B15 2TG, U.K.
}

\begin{abstract}
Summary. A series of 100 modified Kremer tests of human sperm penetration into human cervical mucus was carried out as part of the routine investigation of couples presenting with infertility. The outcome of these tests was significantly correlated with the concentration and progressive motility of the spermatozoa in the semen sample used for the test. Other semen characteristics significantly correlated with the test result were the mean velocity of progression $(V \mathrm{P})$ and the amplitude of lateral head displacement about the axis of progression $(A \mathrm{H})$ of the progressive spermatozoa. Normal sperm morphology was also correlated with the outcome. Using these semen characteristics as the independent variables to predict the test outcome in a discriminant analysis (normal vs abnormal tests), $34.2 \%$ of the variance was accounted for. From the discriminant function equation $75.0 \%$ of the test results could be predicted correctly.

In the 30 cases in which the semen samples used for the tests showed $\geqslant 25 \times 10^{6}$ progressively motile spermatozoa per ml, mean $V \mathrm{P}$ of $\geqslant 25 \mu \mathrm{m} / \mathrm{sec}$ and mean $A \mathrm{H}$ of $\geqslant 7.5 \mu \mathrm{m}, 83.3 \%$ had normal test results. Conversely, all 13 cases for which the semen characteristics were below these limits had abnormal test results.

Therefore, both the concentration of progressively motile spermatozoa and their movement characteristics are significant factors determining the outcome of homologous tests of human sperm-cervical mucus interaction.
\end{abstract}

\section{Introduction}

In recent years much effort has been expended upon the development of tests for evaluating the functional potential of human spermatozoa. Approaches have involved tests of osmoregulatory ability (Jeyendran, Van der Ven, Perez-Pelaez, Crabo \& Zaneveld, 1984), metabolic status by measurement of ATP content (Comhaire et al., 1983), objective determination of quantitative and qualitative aspects of sperm motility (Overstreet, Katz, Hanson \& Fonseca, 1979; Aitken et al., 1983; Aitken, Best, Warner \& Templeton, 1984), the ability of spermatozoa to penetrate bovine (Alexander, 1981; Borghi \& Asch, 1983) and human (Kremer \& Jager, 1982) cervical mucus, and intrinsic fertilizing ability by the use of zona pellucida-free hamster oocytes (Yanagimachi, Yanagimachi \& Rogers, 1976; Yanagimachi, 1984) and human zonae pellucidae (Overstreet, Yanagimachi, Katz, Hayashi \& Hanson, 1980; Overstreet, 1982; Gould et al., 1983).

A major influence of sperm motility upon the fertilizing potential of human spermatozoa has been demonstrated (Aitken et al., 1983, 1984), and also on their ability to penetrate cervical mucus (David et al., 1979; Schats, Aitken, Templeton \& Djahanbakhch, 1984; Aitken, Sutton, Warner \& Richardson, 1985; Katzorke, Propping \& Kolodziej, 1985; Pandya, Mortimer \& Sawers, 1986). Furthermore, aspects of sperm movement such as the velocity of progression and the actual pattern

\footnotetext{
*Present address: Endocrine/Infertility Clinic, Dept of Obstetrics \& Gynaecology, University of Calgary Health
} Sciences Centre, 3330 Hospital Drive N.W., Calgary, Alberta T2N 4N1, Canada. 
of movement have been shown to be closely correlated with sperm penetration into bovine and human cervical mucus (Beauchamp, Galle \& Blasco, 1984; Aitken et al., 1985; Feneux, Serres \& Jouannet, 1985).

The purpose of this study was to investigate the relationship between the motility of human spermatozoa and their penetration into mid-cycle human cervical mucus (using modified Kremer tests) under the conditions of clinical sperm-mucus interaction testing as part of the routine basic investigations of infertile couples. For this specific aim no preselection of patients was made on the grounds of 'normal' semen characteristics.

\section{Materials and Methods}

Semen samples. All semen samples were produced by masturbation at the clinic into sterile plastic containers after a requested 3-day period of prior sexual abstinence. Semen analyses were performed by experienced technicians at $1 \mathrm{~h}$ after ejaculation using standard established procedures (Mortimer, 1985a), and motility indices were calculated as described by Pandya et al. (1986). There was no preselection of subjects for apparent seminological normality.

Objective sperm motility analysis. Dark-ground photomicrographs of 1-sec exposure were taken according to the general principles described by Overstreet et al. (1979). Sperm preparations were made using $10 \mu \mathrm{l}$ semen under a $22 \times 22 \mathrm{~mm}$ coverslip, giving an average preparation depth of $20 \mu \mathrm{m}$. All materials used in making these preparations were kept at $37^{\circ} \mathrm{C}$ and photomicrography was completed within 1-2 min. Developed $35 \mathrm{~mm}$ negative filmstrips were analysed using a semi-automated microcomputer-based system (Photomot: Mortimer, 1986).

The analysis of these photomicrographs provided measurements of the linear velocity of progression of the spermatozoa $(V \mathrm{P})$ and the average lateral head displacement about the axis of progression $(A \mathrm{H})$. These definitions are the same as those used by David, Serres \& Jouannet (1981), and Aitken, Best, Richardson, Djahanbakhch \& Lees (1982). Trajectory parameters were usually determined on 50 progressive spermatozoa per sample. The frequency of rotation, which is equivalent to the frequency of tail beating, cannot be determined reliably from 1 -sec photographic images since tracks showing no obvious lateral head movements (sometimes referred to as 'minimal displacement' tracks or 'rolling' tracks) have to be excluded. In addition, no distinction was made between 'rolling' and 'yawing' tracks as these two categories do not necessarily reflect different patterns of movement (see 'Discussion'). Since the actual three-dimensional trajectory of the sperm head is a helix of elliptical cross-section, many workers in this area now consider that 'rolling' and 'yawing' tracks probably only represent tracks seen perpendicular to the minor or major axes of the ellipse respectively.

Cervical mucus sampling. Procedures were booked predictively for the day of ovulation using an ideal minimum of 5 preceding menstrual cycle lengths (Mortimer \& Templeton, 1982; Mortimer, $1985 b$ ). Sampling of intracervical mucus and evaluation of its quality using the modified Insler score were by standard routine procedures (Mortimer, 1985b).

After exclusion of those patients from whom inadequate quantities of cervical mucus were obtained, 100 couples remained in the study group. Only three sub-normal mucus samples were present in this group, one had an Insler score of $7 / 15$, and two had $\mathrm{pH}$ values of $<7 \cdot 0$. The presence of so few abnormal mucus samples was not considered a significant source of bias in the data, and these cases were therefore retained to maintain the longitudinal completeness of the study population.

Modified Kremer tests. These in-vitro capillary tube tests of sperm penetration into cervical mucus were performed and evaluated as described by Mortimer (1985b). The sperm penetration tests were assessed using an objective scoring system giving a result out of 20 : tests with scores of 
zero were rated as negative and those with scores of $1-8$ as poor. All tests with scores of $<9 / 20$ were considered as abnormal. Normal tests were rated as being average (9-11), good (12-15) or excellent $(\geqslant 16)$. This system was developed empirically to produce results equivalent to the actual 'intuitive' results assigned by experienced observers (Pandya et al., 1986). In addition, the percentage of successful collisions (PSC) score of Katz, Overstreet \& Hanson (1980) was also determined according to their original formula.

Statistical analysis. Data were analysed initially using the STATS PLUS software package (Human Systems Dynamics, Northridge, CA, U.S.A.) with an Apple //e microcomputer (Apple Computer Inc., Cupertino, CA, U.S.A.). Subsequently discriminant analyses were performed using the Statistical Package for the Social Sciences (SPSS: Nie, Hull, Jenkins, Steinbrenner \& Bent, 1975). Multiple regressions used the revised SPSS program (Hull \& Nie, 1981); a value of $P<0.05$ was used as the entry limit for acceptance of predictor variables into these analyses.

Standard statistical conventions are used in the text: $r=$ the simple (Pearson's) correlation coefficient, $R=$ multiple correlation coefficient, $r^{2}$ or $R^{2}=$ the proportion of variance of the dependent variable accounted for by any individual, or group of, independent variable(s).

\section{Results}

Of the 100 tests, 11 were classified as negative, 37 as poor, and 15, 22 and 15 as average, good and excellent respectively. There were wide variations in the semen analysis characteristics among the study population (Table 1), as would be expected for an unselected population of patients.

We have already reported the poor correlation between the mucus penetration and PSC scores, a finding taken to indicate that these two scoring systems were evaluating different aspects of the tests (Pandya et al., 1986). Therefore, in the present study we have assessed the relationships between sperm characteristics and the test results separately for each of these scoring systems. In addition, since the factors of sperm concentration and mean sperm velocity are included in the calculation of the PSC score, a modified PSC score (modPSC) was calculated as the product of the PSC, the concentration of motile spermatozoa, and the mean $V \mathrm{P}$ values. This modPSC value is essentially comparable to the concentration of spermatozoa in the cervical mucus column (see also Aitken et al., 1985).

Table 1. Mean values for the semen analysis characteristics of the 100 samples used in the study along with the linear correlation coefficients for these characteristics (independent variables) against the mucus penetration (SPT) score, the percentage of successful collisions (PSC) score, and the modified PSC score (modPSC, see text) values as dependent variables

\begin{tabular}{lcccc}
\hline Characteristic & Mean (range) & SPT score & PSC score & modPSC score \\
\hline Concentration $\left(10^{6} / \mathrm{ml}\right)$ & $58 \cdot 7(4 \cdot 0-182 \cdot 8)$ & $0 \cdot 487^{* * *}$ & $0 \cdot 226^{*}$ & $0 \cdot 732^{* * *}$ \\
Motility $(\%)$ & $58 \cdot 8(19 \cdot 0-97 \cdot 0)$ & $0 \cdot 296^{* *}$ & $-0 \cdot 128$ & $0 \cdot 320^{* *}$ \\
Progressive motility $(\%)$ & $50 \cdot 0(10 \cdot 0-92 \cdot 0)$ & $0 \cdot 392^{* * *}$ & $-0 \cdot 029$ & $0 \cdot 343^{* * *}$ \\
Motility index & $(47-781)$ & $0 \cdot 308^{* *}$ & $-0 \cdot 072$ & $0 \cdot 357^{* * *}$ \\
Motile sperm conc. $\left(10^{6} / \mathrm{ml}\right)$ & $36 \cdot 5(1 \cdot 3-146 \cdot 2)$ & $0 \cdot 485^{* * *}$ & $0 \cdot 163$ & $0 \cdot 760^{* * *}$ \\
Prog. sperm conc. $\left(10^{6} / \mathrm{ml}\right)$ & $31 \cdot 6(0 \cdot 9-135 \cdot 3)$ & $0 \cdot 524^{* * *}$ & $0 \cdot 191$ & $0 \cdot 765^{* * *}$ \\
Motile sperm conc. index & $(0 \cdot 3-136 \cdot 4)$ & $0 \cdot 435^{* * *}$ & $0 \cdot 155$ & $0 \cdot 727^{* * *}$ \\
Normal morphology $(\%)$ & $41 \cdot 5(7 \cdot 0-74 \cdot 0)$ & $0 \cdot 287^{* *}$ & $0 \cdot 112$ & $0 \cdot 242^{*}$ \\
Normal sperm conc. $\left(10^{6} / \mathrm{ml}\right)$ & $26 \cdot 5(1 \cdot 0-90 \cdot 4)$ & $0 \cdot 450^{* * *}$ & $0 \cdot 230^{*}$ & $0.637^{* * *}$ \\
Mean $V \mathbf{P}(\mu \mathrm{m} / \mathrm{sec})$ & $26 \cdot 5(16 \cdot 9-41 \cdot 5)$ & $0 \cdot 285^{* *}$ & $-0 \cdot 133$ & $0.276^{* *}$ \\
Mean $\mathrm{AH}(\mu \mathrm{m})$ & $7 \cdot 9(4 \cdot 3-12 \cdot 4)$ & $0 \cdot 245^{* *}$ & $0 \cdot 028$ & $-0 \cdot 058$ \\
\hline
\end{tabular}

${ }^{*} P<0.05 ;{ }^{* *} P<0.01 ;{ }^{* * *} P<0.001$. 
Results of linear correlations between the various sperm characteristics and the test scores are presented in Table 1. The use of square-root transformation of variables incorporating the sperm concentration (see Mortimer \& Lenton, 1983) was not found to improve greatly the correlation coefficients, probably due to the wide range of values as well as to the relatively small number of cases.

The large influence of the sperm concentration was most obvious when correlated with the mucus penetration score. In fact no semen characteristic showed a highly significant correlation with the PSC score. When the effects of motile sperm concentration and mean $V \mathbf{P}$ were removed from the PSC, then the modPSC (and hence the concentration of spermatozoa in the mucus column) showed highly significant linear correlations with a number of semen characteristics, especially the concentrations of motile and progressive spermatozoa.

\section{Multiple regression analysis for PSC and modPSC scores}

The relationship between semen characteristics and the PSC score was evaluated for the 100 tests. The mean PSC score was 21.0 ( \pm 15.5 s.d.) with a range of 0 to 50 . Only two variables were accepted into the multiple regression calculation: the concentration of morphologically normal spermatozoa and the mean value of $V \mathrm{P}$ (Table 2). Although this calculation accounted for only $9.3 \%$ of the total variance $\left(R^{2}=0.093\right)$, the final result was moderately significant $(F=4.97$, $P<0.01)$.

The results of a second multiple regression analysis using the modPSC values as the dependent variable are shown in Table 2. In this case only the concentration of progressive spermatozoa was accepted by the program as having a sufficiently significant correlation. This variable alone accounted for $58.6 \%$ of all the variance, and gave an $F$ value of $138.4(P<0.0001)$.

Therefore, the number of spermatozoa entering the mucus is dependent primarily upon the concentration of progressive spermatozoa in the semen sample, with their normal morphology and velocity of progression being of lesser importance.

Table 2. MuAtiple regression of PSC and modified PSC scores on semen characteristics

\begin{tabular}{llccr}
\hline Score & Variable & Multiple $R$ & $R^{2}$ change & $\begin{array}{c}\text { B } \\
\text { (non-standardized) }\end{array}$ \\
\hline PSC & Normal sperm & & & 0.193 \\
& conc. $\left(10^{6} / \mathrm{ml}\right)$ & 0.230 & 0.053 & -0.619 \\
& Mean $V \mathrm{P}(\mu \mathrm{m} / \mathrm{sec})$ & 0.305 & 0.040 & 32.450 \\
& Constant & & & \\
Modified & Progressive sperm & & & 943.875 \\
PSC & conc. $\left(10^{6} / \mathrm{ml}\right)$ & 0.765 & 0.586 & -6611.091 \\
\hline & Constant & & & \\
\hline
\end{tabular}

\section{Discriminant analysis for the mucus penetration score}

Since this score is a discrete variable multiple regressions cannot be used for its prediction. Instead, discriminant analyses were performed using all 100 cases, or after exclusion of the zero scores, i.e. the negative tests (Table 3). Both analyses took the same five semen characteristics: the concentration of progressively motile spermatozoa, the mean values of $V \mathrm{P}$ and $A \mathrm{H}$, the percentage of morphologically normal spermatozoa, and the motile sperm concentration index (see Pandya $e t$ al., 1986). However, their order of incorporation into the two analyses was slightly different.

In the analysis which included all cases the very strong effect of the concentration of progressively motile spermatozoa was again evident (Table 3 ), accounting for $18.5 \%$ of the total 
Table 3. Discriminant analysis results for the prediction of normal vs abnormal mucus penetration tests by semen characteristics in all 100 tests and after exclusion of the 11 negative tests

\begin{tabular}{|c|c|c|c|c|}
\hline Variable & $r^{2}$ & $\begin{array}{c}\text { Increase } \\
\text { in } r^{2}\end{array}$ & $\begin{array}{l}\% \text { of variance } \\
\text { accounted for }\end{array}$ & $\begin{array}{l}\% \text { of all } \\
\text { variance }\end{array}$ \\
\hline \multicolumn{5}{|l|}{ All tests } \\
\hline \multicolumn{5}{|l|}{$\begin{array}{l}\text { Conc. progressive motile } \\
\text { spermatozoa }\left(10^{6} / \mathrm{mll}\right.\end{array}$} \\
\hline Mean $A \mathrm{H}(\mu \mathrm{m})$ & 0.288 & $0 \cdot 103$ & $30 \cdot 1$ & $10 \cdot 3$ \\
\hline \multicolumn{5}{|l|}{ Morphologically } \\
\hline normal $(\%)^{*}$ & 0.321 & 0.033 & $9 \cdot 7$ & $3 \cdot 3$ \\
\hline Mean $V_{\mathbf{P}}(\mu \mathrm{m} / \mathrm{sec})$ & 0.333 & $0 \cdot 012$ & $3 \cdot 5$ & $1 \cdot 2$ \\
\hline MSCI & 0.342 & 0.009 & $2 \cdot 7$ & 0.9 \\
\hline Total & $0 \cdot 342$ & - & $100 \cdot 0$ & $34 \cdot 2$ \\
\hline \multicolumn{5}{|l|}{ Positive tests only } \\
\hline Mean $V \mathrm{P}(\mu \mathrm{m} / \mathrm{sec})$ & $0 \cdot 190$ & - & $52 \cdot 2$ & $19 \cdot 0$ \\
\hline \multicolumn{5}{|l|}{ Morphologically } \\
\hline \multicolumn{5}{|l|}{ Conc. progressive motile } \\
\hline Mean $A \mathrm{H}(\mu \mathrm{m})$ & $\begin{array}{l}0.305 \\
0.353\end{array}$ & $\begin{array}{l}0.038 \\
0 \cdot 050\end{array}$ & $\begin{array}{l}1.5 \\
13.8\end{array}$ & $\begin{array}{l}3.8 \\
5.0\end{array}$ \\
\hline MSCI & 0.363 & 0.010 & $2 \cdot 8$ & $1 \cdot 0$ \\
\hline Total & 0.363 & - & $100 \cdot 0$ & $36 \cdot 3$ \\
\hline
\end{tabular}

MSCI $=$ Motile sperm concentration index (see text).

* Not available for all cases.

variance. The mean value of $A \mathrm{H}$, the second variable included, accounted for a further $10 \cdot 3 \%$ of the total variance. The remaining 3 variables accounted for a further $5.4 \%$ of the variance between them. Therefore $34.2 \%$ of the variance in the mucus penetration score was accounted for, giving a canonical correlation of $0.585(P<0.0001)$.

When negative tests were excluded, the significance of the concentration of progressively motile spermatozoa was greatly reduced (Table 3 ). It was the third most significant predictor variable, and accounted for only $3.8 \%$ of the total variance. The mean value of $V \mathrm{P}$ was the most significant predictor, and accounted for $19.0 \%$ of the total variance. Normal morphology was the second predictor variable, accounting for $7.5 \%$ of the total variance. The mean value of $A \mathrm{H}$ accounted for a further $5 \cdot 0 \%$ of the total variance. The canonical correlation for this analysis was 0.602 $(P<0.0001$ ), with $36.3 \%$ of the total variance being accounted for.

The motile sperm concentration index (MSCI) was the least significant predictor in both analyses, accounting for only 0.9 or $1.0 \%$ of the total variance respectively. The sperm concentration, percentage of progressive spermatozoa and percentage of motile spermatozoa are all included in the calculation of the MSCI, and their variance components would have been accounted for already by the concentration of progressively motile spermatozoa. Therefore the remaining variance component must be due to the other factor in the MSCI calculation, the progressivity rating. Although the progressivity rating is essentially comparable to a combination of $V \mathrm{P}$ and $A H$ measurements, it would appear to include another component responsible for about $1 \%$ of the total variance.

Discriminant function equations were also computed from the two analyses. For all the 100 cases the discriminant function was given by the equation:

(conc. prog. motile $\times 0.0504)+($ mean $A \mathrm{H} \times 0.3827)+($ morphologically normal $\times 0.0223)+$ $($ mean $V \mathrm{P} \times 0.0546)-(\mathrm{MSCI} \times 0.0282)-6.3498$ 
The canonical discriminant functions calculated at the centroids of the groups of normal and abnormal tests (mucus penetration scores of $\geqslant 9$ and $\leqslant 8$ respectively) were 0.6867 and -0.7439 , giving a discriminant limit of $-0 \cdot 03$. Hence an abnormal test would be predicted by a discriminant function of less than this value, and a normal test by a higher value of the discriminant function. Using this discriminant function analysis a correct prediction of normal and abnormal tests was achieved in $75.0 \%$ of cases $(72.9 \%$ of abnormal and $76.9 \%$ of normal test results predicted correctly).

When the negative cases were excluded the discriminant equation became:

$$
\begin{gathered}
\text { mean } V \mathrm{P} \times 0.0903)+(\text { morphologically normal } \times 0.0213)+(\text { conc. prog. motile } \times 0.0439)+ \\
(\text { mean } A \mathrm{H} \times 0.3542)-(\mathrm{MSCI} \times 0.0245)-6.9744
\end{gathered}
$$

The canonical discriminant functions at the normal and abnormal test group centroids were 0.6280 and -0.8826 respectively, giving a discriminant limit of -0.1273 . Using this discriminant function correct classification was predicted in $78.4 \%$ of abnormal tests and $75.0 \%$ of normal tests, giving an overall correct prediction rate of $76.45 \%$.

\section{Definitions of semen quality}

Encouraged by results of the discriminant analyses we tried to define simple limits that could be used clinically to distinguish between semen samples that would be expected to show normal or abnormal sperm-mucus interaction tests. By inspection of the scattergrams of mucus penetration scores on each of the variables, values which provided optimum discrimination between normal and abnormal test results were obtained (Table 4).

Table 4. Limits for semen quality characteristics with regard to the prediction of sperm-mucus interaction test outcome (normal $v s$ abnormal tests)

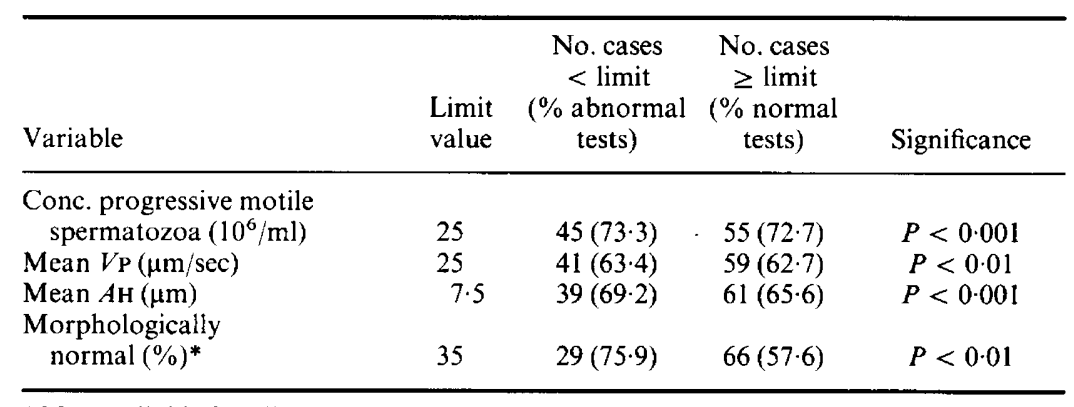

* Not available for all cases.

Because reliable information on the percentage of morphologically normal spermatozoa was unavailable in 5 cases, and in view of the small number of cases with values below the optimum limiting value of $35 \%$ normal forms, this variable was not considered further in this analysis.

Using only the concentration of progressively motile spermatozoa we were able to achieve an overall $73.0 \%$ accurate prediction of test results. Mean $V \mathrm{P}$ and $A \mathrm{H}$ values permitted accurate prediction of $63 \cdot 1 \%$ and $67.4 \%$ of test results respectively. However, the question still remained as to whether each of these variables was accounting for the same variance components. Since the results of the discriminant analyses suggested this to be unlikely we continued this analysis by using these predictor variables in combination.

When the sperm movement characteristics $V_{\mathrm{P}}$ and $A \mathrm{H}$ were used together, 43 cases showed values of $V \mathrm{P} \geqslant 25 \mu \mathrm{m} / \mathrm{sec}$ and $A \mathrm{H} \geqslant 7.5 \mu \mathrm{m}$. Of these 43 tests $72.1 \%$ showed normal results. Of the 23 cases with a $V \mathrm{P}<25 \mu \mathrm{m} / \mathrm{sec}$ and $A \mathrm{H}<7.5 \mu \mathrm{m}$, only $26.1 \%$ showed normal tests. When only 
one of these movement characteristics was below its limiting value ( 34 cases) only $44 \cdot 1 \%$ showed normal test results.

Inclusion of the concentration of progressively motile spermatozoa into the selection gave the best prediction of results. When all these seminal characteristic values were at or above the limiting values ( 30 cases) $83 \cdot 3 \%$ of the tests showed normal results. However, when all values were below these limits (13 cases) all these semen samples showed abnormal mucus penetration results. Therefore, in terms of predicting the outcome of sperm-mucus interaction tests semen parameters of $\geqslant 25 \times 10^{6}$ progressively motile spermatozoa per ml, with mean $V \mathrm{P} \geqslant 25 \mu \mathrm{m} / \mathrm{sec}$ and mean $A \mathrm{H}$ of $\geqslant 7.5 \mu \mathrm{m}$ seemed to characterize 'good' semen. As one or more of these characteristics fell below its limiting value the chance of a normal sperm-mucus interaction test was reduced, so that when all three were below the limits there was little or no chance of a normal test result. Consequently a sample showing $<25 \times 10^{6}$ progressively motile spermatozoa $/ \mathrm{ml}$ with mean $V \mathbf{P}<25 \mu \mathrm{m} / \mathrm{sec}$ and mean $A \mathrm{H}<7.5 \mu \mathrm{m}$ could be described as being 'pathological'.

\section{Discussion}

The results presented here have clearly demonstrated that the outcome of modified Kremer tests of in-vitro sperm-mucus interaction are strongly influenced by semen quality. Previous studies have reported significant correlations between the percentages of motile spermatozoa in semen samples and the outcome of Kremer-type tests (Ulstein \& Fjallbrant, 1976; David et al., 1979; Insler, Bernstein, Glezerman \& Misgav, 1979; Matthews, Makin \& Cox, 1980; Amit et al., 1982; Schats et al., 1984; Aitken et al., 1985). However, the significant influence of sperm concentration, especially the concentration of progressive spermatozoa, has been less well described (Insler et al., 1979; David et al., 1979; Katzorke et al., 1985).

Aitken et al. (1985) have recently reported an extensive statistical analysis of a series of 17 tests of human sperm interaction with bovine cervical mucus using the PSC scoring method of Katz et al. (1980). Since their study employed preselected donors the importance of the concentration of progressively motile spermatozoa may well not have been recognized in their analysis. While there are a number of appreciable differences in the motility analysis systems employed by Aitken $e t$ al. (1985) and the present study (see below), their findings, that sperm movement characteristics related to the velocity of progression and the lateral displacement of the head were the most significant components in multiple regression analyses using the concentration of spermatozoa within the mucus as the dependent variable, are essentially comparable to those reported in the present study.

While it may be more convenient to use bovine cervical mucus there are a number of points that must be borne in mind when interpreting studies using this heterologous penetration system. Principally there is the major concern that while a normal homologous Kremer-type test will show at least $60 \mathrm{~mm}$, and usually $70 \mathrm{~mm}$, depth of sperm penetration into the mucus after $60 \mathrm{~min}$ of incubation, a test using bovine cervical mucus is considered normal if the depth of penetration is only $15 \mathrm{~mm}$ after $90 \mathrm{~min}$ of incubation (Alexander, 1981; Borghi \& Asch, 1983). The final quantitative results using human or bovine cervical mucus must therefore be substantially different.

The PHOTOMOT system for sperm track analysis used in the present study is more closely based upon the measurements of track length and width as reported by Overstreet et al. (1979). An average projected track has a length of $18-20 \mathrm{~mm}$ and a width of 5-6 mm, whereas in Polaroid photomicrographs (Aitken et al., 1982) the dimensions are approximately five times smaller. While the PHOTOMOT system is able to determine the $V \mathbf{P}$ and $A \mathrm{H}$ values with an accuracy of the order of $0.1 \mu \mathrm{m}$ (considering the larger image size, the resolution of the digitizer and the integrative derivation of the average track width), measurements of $A \mathrm{H}$ using the Polaroid system are rather less precise. A failure common to both systems is the inability to derive accurate measurements for the beat frequency, and for this reason we did not consider this characteristic in our study. These frequencies can only be determined for those tracks with large lateral head displacements 
(sometimes referred to as 'yawing'). In narrow tracks the head images are continually overlapped and the individual beats cannot be distinguished. These spermatozoa, which are sometimes referred to as 'rolling', may or may not have the same distribution of beat frequencies as the wider tracks. Therefore deriving a beat frequency value from only those spermatozoa with wide tracks cannot be justified statistically.

However, despite the wide variability of the semen samples comprising the present study population, we were able to identify significant relationships between sperm movement characteristics and the outcome of the sperm-mucus interaction tests. There was no relationship between $V \mathrm{P}$ and $A \mathrm{H}$ values and the PSC score (Table 1), and only $V \mathrm{P}$ was correlated $(r=0.276, P<0.01)$ with the modPSC score. Although the PSC scoring system has been shown to be reliable (Katz, Overstreet, Tom \& Hanson, 1984) we have not found it to be related to the clinical results of the tests which comprised the present study (Pandya et al., 1986). Consequently, and especially in view of its more complex derivation requiring sperm velocity determinations, we have turned more to using the mucus penetration score as a standardized routine procedure.

A strong influence of sperm concentration upon the outcome of modified Kremer tests is to be expected. Obviously the number of spermatozoa that can penetrate the mucus will be correlated positively with the number of spermatozoa in the semen at the mucus interface. However, sperm motility and morphology are also important in determining sperm penetration into cervical mucus (see references cited above, also Mortimer, Leslie, Kelly \& Templeton, 1982a; Mortimer, 1983) and these characteristics of sperm quality are also positively correlated with the total sperm concentration (Mortimer, Templeton, Lenton \& Coleman, 1982b, c).

Furthermore, while correction for the sperm concentration and percentage motility may be a convenient approach for standardizing experimental studies interested only in examining the influence of sperm movement characteristics in isolation (Aitken et al., 1985), it is inappropriate when tests are being performed for clinical purposes. Any prognosis of potential spontaneous fertility cannot be qualified by describing a test as being poor in objective terms but good when the partner's low sperm count is taken into consideration. This is one obvious way in which a reduced sperm count is related clinically to impaired fertility.

The demonstrated relationships between the sperm movement characteristics $V \mathrm{P}$ and $A \mathrm{H}$, which confirm those of Aitken et al. (1985) using a heterologous sperm-mucus penetration system, provide clear evidence that the more detailed evaluation of sperm motility is a potentially valuable contribution in infertility diagnosis. An extreme case of this has been reported by Feneux et al. (1985) who have described 4 sterile men with essentially normal semen characteristics except that the progressive spermatozoa showed very small $A H$ values, and in-vivo and in-vitro sperm-mucus interaction tests were negative or very poor. Therefore, while gross sperm motility can be measured reliably by visual means (Mortimer, 1985a), and objectively using the multiple exposure photomicrography system of Makler (1978, 1980) or by computer-aided tracking (Holt, Moore \& Hillier, 1985), only timed-exposure photomicrography or trajectory reconstruction from either microcinematographic (David et al., 1981) or videomicrographic (Katz \& Overstreet, 1981) recordings can provide measurements of $A \mathrm{H}$. That $V \mathrm{P}$ and $A \mathrm{H}$ account for different variance components in the discriminant analyses (Table 3 ) clearly demonstrates they are measuring different functional aspects of sperm movement. However, although David et al. (1981) reported that $V \mathrm{P}$ and $A \mathrm{H}$ were not significantly correlated, the fundamentals of flagellar locomotion (wave frequency, amplitude, planarity and velocity of propagation) require that they must be related in some way.

Significant correlations have also been reported between $A \mathrm{H}$ values and sperm fertilizing ability in the heterologous system using zona pellucida-free hamster oocytes (Aitken et al., 1982, 1983, 1984), and also with the prediction of spontaneous pregnancies in patients with unexplained infertility (Aitken et al., 1984). Clearly sperm movement is an extremely important facet of sperm functional ability and can no longer be ignored in experimental or clinical studies.

We are not suggesting that sperm movement characteristics should be evaluated as part of the basic investigations for every infertile couple. Nor are we suggesting that homologous sperm- 
mucus interaction testing could be replaced by the evaluation of sophisticated semen characteristics. On the contrary, if careful in-vitro tests of sperm-mucus interaction show normal results there is probably no reason to suspect defective sperm motility. If no other causes of a couple's infertility are found then recourse to more elaborate tests of sperm function, such as fertilizing ability determinations (Yanagimachi, 1984) or laparoscopic sperm recovery (Templeton \& Mortimer, 1982), may be appropriate. While in-vivo sperm-mucus interaction tests (post-coital tests) do not seem to correlate with the success or failure of sperm transport to the site of fertilization (Templeton \& Mortimer, 1982), if the modified Kremer test shows an abnormal result, and the finding is confirmed upon repeat testing in a subsequent cycle, then, providing that all necessary tests for immunologically-based cervical factors have been performed (Mortimer, 1985b), sperm movement analysis would seem to be appropriate. Only from such thorough in-vitro testing, in conjunction with careful clinical follow-up (particularly the occurrence of spontaneous pregnancies), will it be possible to ascertain the true clinical significance of 'abnormal' findings in spermmucus interaction tests. While we do agree with the conclusion of Shats et al. (1984) that impaired sperm penetration into cervical mucus is more often due to the spermatozoa than the mucus itself, specific causes of infertility at the cervical level do exist and their correct diagnosis or exclusion must be an intrinsic part of the definition of unexplained infertility.

We thank Mr David Persaud of the Nat Christie Unit for the Study of Human Reproduction (Calgary) for help with the discriminant function and multiple regression analyses.

\section{References}

Aitken, R.J., Best, F.S.M., Richardson, D.W., Djahanbakhch, O. \& Lees, M.M. (1982) The correlates of fertilizing capacity in normal fertile men. Fert. Steril. 38, 68-76.

Aitken, R.J., Warner, P., Best, F.S.M., Templeton, A.A., Djahanbakhch, O., Mortimer, D. \& Lees, M.M. (1983) The predictability of subnormal penetrating capacity of sperm in cases of unexplained infertility. Int. J. Androl. 6, 212-220.

Aitken, R.J., Best, F.S.M., Warner, P. \& Templeton, A.A. (1984) A prospective study of the relationship between semen quality and fertility in cases of unexplained infertility. J. Androl. 5, 297-303.

Aitken, R.J., Sutton, M., Warner, P. \& Richardson, D.W. (1985) Relationship between the movement characteristics of human spermatozoa and their ability to penetrate cervical mucus and zona-free hamster oocytes. J. Reprod. Fert. 73, $441-449$.

Alexander, N.J. (1981) Evaluation of male infertility with an in vitro cervical mucus penetration test. Fert. Steril. 36, 201-208.

Amit, A., Bergman, A., Yedwab, G., David, M.P., Homonnai, T.Z. \& Paz, G. (1982) Human sperm penetration into cervical mucus in vitro: correlation between its quality, penetration capacity and velocity. Gynecol. Obstet. Invest. 14, 283-291.

Beauchamp, P.J., Galle, P.C. \& Blasco, L. (1984) Human sperm velocity and postinsemination cervical mucus test in the evaluation of the infertile couple. Archs Androl. 13, 107-112.

Borghi, M.R. \& Asch, R.H. (1983) Human sperm penetration in bovine cervical mucus: clinical studies $I . J$. Androl. 4, 316-318.

Comhaire, F., Vermeulen, L., Ghedira, K., Mas, J., Irvine,
S. \& Callipolitis, G. (1983) Adenosine triphosphate in human semen: a quantitative estimate of fertilizing potential. Fert. Steril. 40, 500-504.

David, G., Serres, C. \& Jouannet, P. (1981) Kinematics of human spermatozoa. Gamete Res. 4, 83-95.

David, M.P., Amit, A., Bergman, A., Yedwab, G., Paz, G.F. \& Homonnai, Z.T. (1979) Sperm penetration in vitro: correlations between parameters of sperm quality and the penetration capacity. Fert. Steril. 32, 676-680.

Feneux, D., Serres, C. \& Jouannet, P. (1985) Sliding spermatozoa: a dyskinesia responsible for human infertility? Fert. Steril. 44, 508-511.

Gould, J.E., Overstreet, J.W., Yanagimachi, H., Yanagimachi, R., Katz, D.F. \& Hanson, F.W. (1983) What functions of the sperm cell are measured by in vitro fertilization of zona-free hamster eggs? Fert. Steril. 40, 344-352.

Holt, W.V., Moore, H.D.M. \& Hillier, S.G. (1985) Computer-assisted measurement of sperm swimming speed in human semen: correlation of results with in vitro fertilization assays. Fert. Steril. 44, 112-119.

Hull, C.H. \& Nie, N.H. (1981) SPSS Update 7-9. New Procedures and Facilities for Releases 7-9. McGrawHill Book Co., New York.

Insler, V., Bernstein, D., Glezerman, M. \& Misgav, N. (1979) Correlation of seminal fluid analysis with mucus-penetrating ability of spermatozoa. Fert. Steril. 32, 316-319.

Jeyendran, R.S., Van der Ven, H.H., Perez-Pelaez, M., Crabo, B.G. \& Zaneveld, L.J.D. (1984) Development of an assay to assess the functional integrity of the human sperm membrane and its relationship to other semen characteristics. J. Reprod. Fert. 70, 219-228. 
Katz, D.F. \& Overstreet, J.W. (1981) Sperm motility assessment by videomicrography. Fert. Steril. 35, $188-193$.

Katz, D.F., Overstreet, J.W. \& Hanson, F.W. (1980) A new quantitative test for sperm penetration into cervical mucus. Fert. Steril. 33, 179-186.

Katz, D.F., Overstreet, J.W., Tom, R.A. \& Hanson, F.W. (1984) Factors influencing the penetration of spermatozoa into cervical mucus in vitro. Gamete Res. 9, 167-174.

Katzorke, T., Propping, D. \& Kolodziej, F.B. (1985) Gekreuzter Sperm-Penetration-Meter Test Prognostische Wertigkeit bei der androgenen Subfertilität. Andrologia 17, 234-240.

Kremer, J. \& Jager, S. (1982) Tests for the investigation of sperm-cervical mucus interaction. In Human Fertility Factors, pp. 229-243. Eds A. Spira \& P. Jouannet. INSERM, Paris.

Makler, A. (1978) A new multiple exposure photography method for objective spermatozoal motility determination. Fert. Steril. 30, 192-199.

Makler, A. (1980) Use of the elaborated multiple exposure photography (MEP) method in routine sperm motility analysis and for research purposes. Fert. Steril. 33, 160-166.

Matthews, C.D., Makin, A.F. \& Cox, L.W. (1980) Experience with in vitro sperm penetration testing in infertile and fertile couples. Fert. Steril. 33, 187-192.

Mortimer, D. (1983) Sperm transport in the human female reproductive tract. Oxford Rev. Reprod. Biol. 5,3061 .

Mortimer, D. (1985a) The male factor in infertility: Part 1: Semen analysis. In Current Problems in Obstetrics, Gynecology and Fertility, Vol. 8, No. 7, pp. 1-87. Year Book Medical Publishers, Chicago.

Mortimer, D. (1985b) The male factor in infertility: Part 2: Sperm function testing. In Current Problems in Obstetrics, Gynecology and Fertility, Vol. 8, No. 8, pp. 1-75. Year Book Medical Publishers, Chicago.

Mortimer, D. (1986) A microcomputer-based semiautomated system for human sperm movement analysis. Clin. Reprod. Fert. 4 (in press).

Mortimer, D. \& Lenton, E.A. (1983) Distribution of sperm counts in suspected infertile men. J. Reprod. Fert. 68, 91-96.

Mortimer, D. \& Templeton, A.A. (1982) Sperm transport in the human female reproductive tract in relation to semen analysis characteristics and time of ovulation. J. Reprod. Fert. 64, 401-408.

Mortimer, D., Leslie, E.E., Kelly, R.W. \& Templeton, A.A. (1982a) Morphological selection of human spermatozoa in vivo and in vitro. J. Reprod. Fert. 64, 391-399.
Mortimer, D., Templeton, A.A., Lenton, E.A. \& Coleman, R.A. (1982b) Semen analysis parameters and their interrelationships in suspected infertile men. Archs Androl. 8, 165-171.

Mortimer, D., Templeton, A.A., Lenton, E.A. \& Coleman, R.A. (1982c) Semen analysis parameters of a population of suspected infertile men. In Human Fertility Factors, pp. 91-96. Eds A. Spira \& P. Jouannet. INSERM, Paris.

Nie, N.H., Hull, C.H., Jenkins, J.G., Steinbrenner, K. \& Bent, D.H. (1975) Statistical Package for the Social Sciences. McGraw Hill, New York.

Overstreet, J.W. (1982) Evaluation of sperm function by tests of sperm ovum interaction in vitro. In Human Fertility Factors, pp. 263-280. Eds A. Spira \& P. Jouannet. INSERM, Paris.

Overstreet, J.W., Katz, D.F., Hanson, F.W. \& Fonseca, J.R. (1979) A simple inexpensive method for objective assessment of human sperm movement characteristics. Fert. Steril. 31, 162-172.

Overstreet, J.W., Yanagimachi, R., Katz, D.F., Hayashi, K. \& Hanson, F.W. (1980) Penetration of human spermatozoa into the human zona pellucida and the zona-free hamster egg: a study of fertile donors and infertile patients. Fert. Steril. 33, 534542.

Pandya, I.J., Mortimer, D. \& Sawers, R.S. (1986) A standardized approach for evaluating the penetration of human spermatozoa into cervical mucus in vitro. Fert. Steril. 45, 357-365.

Schats, R., Aitken, R.J., Templeton, A.A. \& Djahanbakhch, O. (1984) The role of cervical mucussemen interaction in infertility of unknown aetiology. Br. J. Obstet. Gynaecol. 91, 371-376.

Templeton, A.A. \& Mortimer, D. (1982) The development of a clinical test of sperm migration to the site of fertilization. Fert. Steril. 37, 410415.

Ulstein, M. \& Fjallbrant, B. (1976) In vitro tests of sperm penetration in cervical mucus. In Human Semen and Fertility Regulation in Men, pp. 383-388. Ed. E. S. E. Hafez. C. V. Mosby Co., St Louis.

Yanagimachi, R. (1984) Zona-free hamster eggs: Their use in assessing fertilizing capacity and examining chromosomes of human spermatozoa. Gamete Res. 10, 187-232.

Yanagimachi, R., Yanagimachi, H. \& Rogers, B.J. (1976) The use of zona-free animal ova as a test-system for the assessment of the fertilizing ability of human spermatozoa. Biol. Reprod. 15, 471-476.

Received 28 November 1985 